\title{
DIVERSIDAD FUNCIONAL, JUSTICIA Y NUEVA GENÉTICA: UNMARCO NORMATIVO ÉTICO-POLÍTICO
}

\author{
FUNCTIONAL DIVERSITY, JUSTICE AND NEW GENETICS: \\ AN ETHICAL-POLITICAL NORMATIV FRAME
}

\author{
Manuel Aparicio Payá ${ }^{1}$ \\ IES Aljada, Puente Tocinos (Murcia)
}

Recibido: 31/ 03/ 2016

Aceptado: 31/ 05/ 2016

Resumen: Este artículo pretende armonizar el reconocimiento de la dignidad de las personas con diversidad funcional y la prevención de la vulnerabilidad genética. En un primer momento, se reorienta la propuesta de Buchanan y otros sobre justicia distributiva de activos naturales desde la concepción deliberativa de la democracia. Posteriormente, se propone un marco normativo ético-político para la genética terapéutica, siguiendo la ética del discurso de Habermas y Cortina.

Palabras clave: Ética discursiva, diversidad funcional, democracia deliberativa, nueva genética, justicia.

\begin{abstract}
This article presents that is compatible to recognise the dignity of people with functional diversity and prevent the genetic vulnerability. First, the Buchaman's distributive justice theory of natural characteristics and other are adapted and modified from the Deliberative democracy theory. After that, it is proposed a ethic and politic framework for the genetic therapy, following the Habermas's and Cortina's ethics discourse.
\end{abstract}

Keywords: Discourse ethics, functional diversity, Deliberative democracy, genetic new, justice.

1. (maparici2@yahoo.es, mapaya31@gmail.com) Profesor de Filosofía- IES Aljada (Puente Tocinos, Murcia). Licenciado en Filosofía y CC. Educación- Universidad de Valencia. Máster de "Pensamiento Contemporáneo"- Universidad de Murcia. Doctor en Filosofía por la Universidad de Murcia. 


\section{Introducción}

Es un hecho histórico que la vieja eugenesia, surgida a finales del siglo XIX y desarrollada hasta años después de la Segunda Guerra Mundial, tuvo dramáticas repercusiones en las personas con diversidad funcional $^{2}$. Es sabido que la brutal aplicación de las ideas eugenésicas en la Alemania nazi conllevó el exterminio de miles de personas con diferentes tipos de diversidad funcional. El eugenismo, extendido también por el mundo anglosajón y por los países nórdicos, sirvió de base teórica para la promulgación de legislaciones que inducían la esterilización obligatoria de personas con enfermedades mentales, con deformaciones corporales hereditarias o con discapacidad intelectual. Influyó, así mismo, en la limitación a tales personas del derecho a formar libremente una familia o en impedir su derecho a la crianza de los hijos biológicos. Este sombrío balance impulsado por la vieja eugenesia muestra que la búsqueda de la «mejora» genética de la humanidad quedó finalmente trastocada en la implementación de legislaciones ancladas en prejuicios hacia aquellos con una constitución bio-psicológica considerada «débil» o «indeseable». La desvalorización de las personas con diversidad funcional, clasificadas socialmente como «inferiores», respondía a la incrustación de elementos ideológicos en el seno de opiniones que se pretendían «científicas». Así pues, lo que caracterizó a la vieja eugenesia fue: 1) la desvalorización ideológica de ciertos grupos de personas, socialmente estigmatizadas, 2) la creación de legislaciones estatales impulsoras de medidas coercitivas dirigidas a tales grupos y 3) la violación de los derechos fundamentales de los integrantes de dichos grupos.

A finales del siglo XX, impulsada por el afán de dominio que subyace en la racionalidad científico-técnica, surge la denominada nueva genéti$c a$, gracias al desarrollo de la medicina y las biotecnologías. Su aplicación ha hecho posible el surgimiento de nuevas técnicas terapéuticas, a la vez que ha abierto el camino, todavía incipientemente recorrido, para la "mejora biológica» del ser humano ${ }^{3}$. Los defensores de estas nuevas técnicas genéticas, conscientes de los acontecimientos históricos, marcan distancia con la vieja eugenesia. En tal sentido, la denominada eugenesia liberal $^{4}$ rechaza la violación de derechos fundamentales de los seres humanos, defiende el pluralismo en cuanto a la determinación de modelos genéticos

2. Buchanan, A. y otros: Genética y Justicia, Madrid, Cambridge University Press, 2002, cap. 2; Pfeiffer, D.: "Eugenesia y discriminación en el ámbito de la discapacidad" en Barton, L. (comp.), Superar las barreras de la discapacidad, Madrid, Morata, 2008, pp. 86-106.

3. Jouve, N.: "De la eugenesia y la biotecnología al mejoramiento humano" en Cortina, A. y Serra, M. A. (coords.): Humanidad. Desafíos éticos de las tecnologías emergentes, Madrid, Ediciones Internacionales Universitarias, 2016, pp. 203-229.

4. Sandel, M.: Contra la perfección, Barcelona, Marbot ediciones, 2015, pp. 127 y ss.

Thémata. Revista de Filosofía $\mathrm{N}^{\circ} 55$ (2017) pp.: 65-82. 
ideales y deja en manos de la libertad de mercado la selección de las características genéticas. Son, pues, partidarios de una genética desarrollada en un previo marco de justicia ${ }^{5}$.

Sin embargo, hay autores ${ }^{6}$ que, desde la perspectiva de la diversidad funcional, efectúan críticas ante las consecuencias abiertas por la nueva genética, considerando que las prácticas que conlleva esconden, en el fondo, la negación del valor de las personas con diversidad funcional. Estos autores denuncian que el supuesto subyacente en el uso de tales técnicas es una valoración de corte excluyente: los seres humanos con errores genéticos tienen una vida que no merece ser vivida. Así, pues, el núcleo del rechazo planteado al uso de las intervenciones genéticas radica, a su entender, en la consideración de las consecuencias que su empleo tiene en el cuestionamiento de la dignidad de las personas con diversidad funcional.

En este trabajo abordamos la cuestión polémica, tratada por $\mathrm{Bu}$ chanan, Brock, Daniels y Wikler en su obra Genética y justicia, de la prevención terapéutica de la diversidad funcional mediante intervenciones genéticas. Entendemos, en línea con lo señalado por Buchanan y otros, que el uso de la genética terapéutica — cuando está sujeta a condiciones ético-políticas adecuadas - es compatible con el respeto a la dignidad de las personas con diversidad funcional. A pesar de lo cual discrepamos de algunos de los argumentos que dichos autores defienden. En tal sentido, exponemos sintéticamente los argumentos críticos aducidos por Buchanan y otros frente a los argumentos esgrimidos por los defensores de las personas con diversidad funcional, aportando también nuestro punto de vista. Posteriormente, realizamos una reorientación de su planteamiento de justicia distributiva de activos naturales. Abordamos dicha reorientación desde la propuesta de democracia deliberativa realizada por la ética discursiva (Habermas, Cortina). Apoyándonos en esta concepción, justificamos normativamente que las aportaciones de la nueva genética al marco cooperativo vigente en la sociedad no deben ir en detrimento de las transformaciones sociales requeridas para el reconocimiento de la igual dignidad y de los iguales derechos de las personas con diversidad funcional. Concluimos el artículo proponiendo, a partir de la ética dialógica (Habermas, Cortina) y de la concepción de la justicia de A. Honneth, un marco normativo ético-político para la genética terapéutica. Al insertar la nueva genética en dicho marco normativo, tratamos de subrayar la dignidad in-

5. Buchanan, A. y otros: op. cit., pp. 53-56.

6. Cfr. Romañach, J.: «Las personas con discapacidad ante la nueva genética», en García-Marzá, D. y González, E. (ed.): Entre la ética y la política: éticas de la sociedad civil. Actas del XII Congreso de la Asociación Española de Etica y Filosofía Política, Castelló, Publicacions de la Universitat Jaume I, Servei de Comunicació i Publicacions, 2003.

Thémata. Revista de Filosofía N55 (2017) pp.: 65-82. 
trínseca de todas las personas con diversidad funcional, al tiempo que se evita una recaída en los peligros de la vieja eugenesia.

\section{Las personas con diversidad funcional y la nueva genética}

La nueva genética ha suscitado gran cantidad de críticas ${ }^{7}$. No puede obviarse, ciertamente, su posible uso ideológico. Es lo que ocurre cuando se la concibe como una especie de mecanismo de redención de una amplia variedad de problemas humanos. En tal sentido, en los debates actuales sobre mejoramiento humano se percibe una nueva aplicación del mito del cuerpo perfecto $^{8}$ que jalona buena parte de la cultura occidental. Como señala Sandel, esta nueva utopía, impulsada por los desarrollos científicos más recientes, apela a la idea de un progresivo e ilimitado perfeccionamiento del cuerpo humano. No obstante, aunque no se adopte una posición ingenua y se depuren los riesgos ideológicos que pudieran conllevar, entendemos que, aplicadas con un control social y dentro de un marco de justicia, no tendrían por qué ser necesariamente rechazadas tales técnicas. La razón fundamental es aquella referida a los beneficios terapéuticos que pueden —o pudieran en el futuro- conllevar. Esta es, por ejemplo, la postura defendida por Nussbaum ${ }^{9}$. A pesar de que esta autora reconoce que las vidas de muchas personas con diversidad funcional son extremadamente valiosas, deja abierta la puerta al uso de estas nuevas biotecnologías. También Sandel, desde un planteamiento crítico con el enfoque liberal, establece una diferencia entre perfeccionamiento y terapia. Este pensador considera que el último de los usos está plenamente justificado, en la medida en que la intervención correctora humana en la naturaleza, ya realizada desde siglos atrás por la medicina, resulta necesaria. Por lo cual, el uso terapéutico no tiene por qué ser condenado. Puede decirse, pues, que la idea que subyace en los planteamientos que hemos señalado es aquella que defiende que la corrección genética de la diversidad funcional no resulta incompatible con la salvaguarda de la dignidad de las per-

7. Sandel, M.: op. cit. Cfr. Cortina, A. y Serra, M. A. (coords.): op. cit. Tales críticas se centran en señalar los límites del poder de la ciencia, en el rechazo al supuesto reduccionista en la concepción del ser humano o en la instrumentalización del mismo a que, a su juicio, apuntan tales técnicas

8. Nussbaum, M.: El ocultamiento de lo humano, Buenos Aires, Katz, 2006. Para una visión del mito en la cultura occidental, desde la perspectiva de la diversidad funcional, puede verse Barnes, C.: "Las teorías de la discapacidad y los orígenes de la opresión de las personas discapacitadas en la sociedad occidental" en Barton, L. (comp.): Discapacidad y sociedad. Madrid, Morata, 1998.

9. Nussbaum, M.: El ocultamiento, cit., p. 352.

Thémata. Revista de Filosofía $\mathrm{N}^{\circ} 55$ (2017) pp.: 65-82. 
sonas nacidas que presentan algún tipo de diversidad funcional. Más bien, dicha dignidad hace que, cuando están disponibles, dichas técnicas deban estar al alcance de acuerdo con unos mínimos de justicia.

Por su parte, Buchanan, Brock, Daniels y Wikler sitúan la nueva genética en el campo de la colonización de lo natural por lo justo. Entienden, no obstante, que las teorías de la justicia distributiva (Rawls, Dworkin o Sen) no han considerado la posibilidad de intervenir directamente en la lotería natural, sino que únicamente han tenido en cuenta la compensación de las desigualdades naturales. Sin embargo, consideran que los avances científicos abren la posibilidad de realizar intervenciones genéticas terapéuticas en seres humanos. Esta nueva realidad obliga a revisar la idea de que la justicia distributiva ha de quedar limita a la distribución de bienes sociales. Entienden, por el contrario, que la preocupación por lo justo ha de alcanzar también a la distribución de activos naturales. Desde su perspectiva, defienden que es una exigencia de justicia prevenir o mejorar limitaciones graves a las oportunidades, debidas a la diversidad funcional, usando, para ello, las correspondientes intervenciones genéticas.

Buchanan y otros rechazan los argumentos propuestos por los defensores de las personas con diversidad funcional, quienes entienden que la genética terapéutica supone una amenaza a la dignidad de las personas con diversidad funcional ya nacidas, considerando también que tales técnicas pondrían en peligro los esfuerzos sociales que ya han sido puestos en marcha para conseguir un trato justo a dichas personas por parte de la sociedad. En el capítulo 7 de Genética y justicia exponen sintéticamente tales argumentos y los contrarrestan. A continuación, recogemos la exposición y la crítica de los citados argumentos, añadiendo también nuestra valoración de los mismos:

1) Quienes apoyan a las personas con diversidad funcional argumentan que la línea de separación entre la "antigua genética» y la «nueva genética» no está claramente definida, en la medida en que ambas promueven la exclusión ${ }^{10}$. En el primer caso, se excluía a individuos defectuosos, al concebirlos como una amenaza para la humanidad, ya que se consideraba que el plasma germinal que poseían era inferior. La «nueva genética» tendría un objetivo similar al excluir a individuos con genes defectuosos, no únicamente de ciertos bienes, sino, fundamentalmente, de la igual consideración debida a todos los miembros de la comunidad humana.

Estos autores vienen a reconocer que, aunque hay diferencias entre ambas etapas históricas de la genética, también hay una parte de verdad en la argumentación de los defensores de las personas con diversidad funcional. Entienden que la nueva genética adolece de una retórica

10. Buchanan, A. y otros: op. cit., pp. 244-247.

Thémata. Revista de Filosofía $\mathrm{N}^{\circ} 55$ (2017) pp.: 65-82. 
de progreso: pretende ser universalista e incluyente, buscando prevenir el sufrimiento de toda la humanidad mediante la erradicación de las enfermedades genéticas. Sin embargo, consideran que no toma en consideración algunas cuestiones de justicia o de exclusión. No obstante, a pesar del potencial negativo que conlleva la nueva genética, piensan que también puede crear oportunidades para incluir a más personas como participantes eficaces en la cooperación social.

Desde nuestro punto de vista podemos afirmar, no obstante, que si, como indica $\mathrm{Sen}^{11}$, la mayor parte de las diversidades funcionales existentes son provocadas por la pobreza extrema en países en desarrollo, son consecuencias de las guerras o son el resultado de algún tipo de accidente, entonces las transformaciones sociales resultan, ciertamente, más prioritarias. Tales transformaciones se concretan en las tareas de prevención y en la implementación de un conjunto de derechos que deben ser respetados de acuerdo con unos mínimos decentes. Todo ello con independencia de que se avance en las intervenciones genéticas.

2) Un segundo argumento ${ }^{12}$ presentado por defensores de las personas con diversidad funcional es de naturaleza social: la aplicación de las técnicas genéticas supondrá la disminución del número de personas con diversidad funcional, lo que puede conllevar la pérdida del interés social para ayudar a quienes tienen esta característica. Tal disminución de la ayuda social terminará por dificultar sus vidas.

Para rechazar este argumento Buchanan y otros alegan que: a) no está empíricamente respaldado; b) se ha dado un caso contrario: en el programa de reducción de la talasemia en Grecia no se produjo dicha disminución; c) el movimiento social de las personas con diversidad funcional ha hecho comprender al conjunto de la sociedad la necesidad que tienen del apoyo social; d) otras personas pueden tener un interés legítimo en usar las intervenciones genéticas para corregir una diversidad funcional, lo que no sería cuestionable moralmente, a pesar de la pérdida de la ayuda que pudiera producirse; e) si el riesgo de perder ayudas fuese una buena razón para no realizar intervenciones genéticas, también lo sería para no realizar intervenciones médicas. Sin embargo, es moralmente obligatorio evitar, por ejemplo, que un niño pueda quedarse ciego. En suma, piensan que, aunque haya una obligación social de mantener el apoyo a las personas con diversidad funcional, de ello no se sigue que sea válida la reivindi-

11. Sen, A.: La idea de la justicia, Madrid, Taurus, 2010, p. 289.

12. Buchanan, A. y otros: op. cit., pp. 248-251.

Thémata. Revista de Filosofía $\mathrm{N}^{\circ} 55$ (2017) pp.: 65-82. 
cación de que la sociedad debe asegurarse de que no disminuya el número de tales personas.

Desde nuestro punto de vista entendemos que este segundo argumento de los defensores de las personas con diversidad funcional es más débil y vuelve a centrarse en la preocupación por el mantenimiento y progresión de los cambios sociales que, en los últimos tiempos, han contribuido a la justa eliminación de numerosas barreras que introducen dificultades en quienes tienen algún tipo de diversidad funcional. Aunque no cabe hablar de progreso continuo, puede decirse que el nivel de conciencia social y moral alcanzado difícilmente puede quedar invertido por la aplicación de tales técnicas. Entendemos, además, que en la lucha por el reconocimiento (Honneth) debe primar, más que el poder del grupo social o el número de sus componentes, la justificación que puedan tener las demandas de justicia para las que se pide dicho reconocimiento, es decir, las razones que la tornan en legítima ${ }^{13}$.

3) Otro argumento relevante ${ }^{14}$ es aquel que está centrado en el valor interno de la vida de las personas con diversidad funcional. Para sus defensores, las intervenciones genéticas vienen a expresar un juicio negativo hacia ellas. Desde este punto de vista, el juicio implícito en tales intervenciones expresaría que únicamente las vidas de las personas genéticamente perfectas tienen valor. Lo cual implica que se está suponiendo que las vidas de las personas con diversidad funcional grave no merecen la pena vivirse. Por tanto, su existencia quedaría cuestionada.

Buchanan y otros justifican que no queda demostrado que, siempre que se produce una intervención para prevenir la diversidad funcional en una persona, se haga un juicio que exprese la creencia de que la vida de las personas con diversidad funcional no es valiosa y no merece ser vivida, de modo que sólo los individuos que son perfectos tendrían derecho a existir. Consideran que es admisible usar las intervenciones genéticas sin defender, en contrapartida, que las personas con diversidad funcional no deben existir.

Desde nuestro punto de vista, podría añadirse, en primer lugar, que este argumento en apoyo a las personas con diversidad funcional no tiene en cuenta la perspectiva moral. En ese sentido, si adoptamos una perspectiva moral kantiana, estamos afirmando el igual valor absoluto (dignidad) de toda persona. En la versión de la ética dialógica, para juzgar si las intervenciones genéticas son justas o no, tenemos ya siempre que partir del reconocimiento de las personas con diversidad funcional como interlocutores válidos, sean reales o virtuales, con independencia de sus

13. Cortina, A.: Ética de la razón cordial, Oviedo, Ediciones Nobel, 2009, pp. 168-189.

14. Buchanan, A. y otros: op. cit., pp. 253-262.

Thémata. Revista de Filosofía $\mathrm{N}^{\circ} 55$ (2017) pp.: 65-82. 
características fácticas y, por tanto, como seres con los mismos derechos pragmáticos. Por eso mismo, cuando las intervenciones genéticas se usan evitando la instrumentalización de la persona, con un adecuado control social y con mínimos de justicia, no puede decirse que resulten contrarias a la dignidad humana ni de quien se somete a estas técnicas ni de otras personas ya nacidas ${ }^{15}$. En segundo lugar, las luchas por el reconocimiento de las personas con diversidad funcional han logrado, en el plano político, mejorar el reconocimiento de sus derechos humanos, haciendo que las sociedades actuales se transformen para facilitar la inclusión social. En cierto modo, porque se trata de luchas morales que apelan al reconocimiento de la igual dignidad de todas las vidas humanas.

4) También se ha utilizado el argumento de la diversidad cultural ${ }^{16}$ para atacar las intervenciones genéticas. En defensa de las personas con diversidad funcional se aduce, por ejemplo, que la comunidad de personas sordas ha desarrollado una cultura valiosa (que incluye un lenguaje propio) que no supone limitación alguna y que, por el contrario, cuenta con las suficientes oportunidades. Por eso mismo, las intervenciones médicas o la prevención genética suponen un deterioro de la riqueza que supone la diversidad humana.

Buchanan y otros consideran que: a) Este argumento es difícilmente generalizable a otros tipos de diversidad funcional; b) Aunque el argumento tiene en cuenta los bienes aportados por la pertenencia a la comunidad de personas sordas, no toma en consideración las limitaciones de las oportunidades que conlleva la sordera; c) Los beneficios que pueden derivarse de la pertenencia a la comunidad de sordos no es una razón suficiente para que los padres, que no se ven directamente afectados, elijan por un hijo que no puede dar el consentimiento.

La cuestión problemática que, desde nuestro punto de vista, subyace a este argumento es la cuestión del consentimiento informado. Son los padres quienes tienen que tomar una decisión que afecta al niño. La decisión que se tome, en la medida en que afecta a una vida individual, no debería basarse exclusivamente en el valor de la diversidad cultural. Pueden apuntarse algunas razones que lo justifican: a) Aunque la cultura permite dar identidad el individuo, es este, en último término, quien merece protección de forma prioritaria; b) Quizás ese individuo podría preferir adoptar, en el futuro, una cultura distinta, lo cual —en el caso de la elección de la sordera - ya quedaría fuera de su alcance, y c) La cultura no

15. Como señala P. Ricoeur, "bajo las tinieblas de la locura permanece el valor de la enfermedad y el del enfermo", Lo justo 2, Madrid, Trotta, 2006, p. 181. Analógicamente, es moralmente compatible ayudar a superar la pobreza salvaguardando la dignidad de la persona pobre.

16. Buchanan, A. y otros: op. cit., pp. 262-265.

Thémata. Revista de Filosofía №55 (2017) pp.: 65-82. 
puede ser concebida como una totalidad homogénea y cerrada, por lo que pueden tenderse puentes entre la cultura de la comunidad de sordos y la cultura de los oyentes (por ejemplo, facilitando que estos últimos conozcan el lenguaje de signos). Por otra parte, como señala Nussbaum, una cosa es afirmar que la vida de las personas sordas pueden ser tan rica como la de las personas oyentes, de forma que ambas requieran el apoyo de los mínimos de funcionamiento humano, y otra diferente es sostener que, si existe un procedimiento médico que permite evitar la sordera, este se le niegue a un individuo que no está en disposición de decidir por sí mismo. Lo cual es independiente de que la sociedad siga dando apoyo a la cultura de las personas sordas. Dicho apoyo, concretado con recursos o con medidas para promover y desarrollar la cohesión del colectivo de personas sordas, es una demanda legítima ya que apela al principio de igualdad jurídica, de forma que el Estado elimine los obstáculos para la reproducción cultural del grupo, en condiciones de igualdad con grupos culturales diferentes ${ }^{17}$.

\section{Reorientación de la justicia distributiva de activos natu- rales desde un marco de democracia deliberativa}

El conjunto de los argumentos ofrecidos por Buchanan y otros trata de justificar la necesidad de llevar a cabo intervenciones genéticas también otro tipo de intervenciones médicas - para evitar la aparición de diferentes tipos de diversidad funcional. En tal sentido, Norman Daniels defiende la idea de que la enfermedad constituye una «desviación adversa respecto al funcionamiento normal de la especie» ${ }^{18}$. Por tanto, también la enfermedad genética, que está a la base de la diversidad funcional, supone una alteración de ese funcionamiento normal de la especie $\mathrm{y}$, desde su punto de vista, una limitación de las oportunidades. De todo ello se deriva un derecho moral a la protección de la salud. Desde ese punto de vista, proponen que se establezcan políticas sociales para que las intervenciones genéticas se garanticen a quienes las necesiten. La justicia distributiva exige este acceso a tales servicios porque «es necesario para mantener una igualdad de oportunidades equitativa, que la enfermedad amenaza con socavar» ${ }^{19}$.

Sin embargo, estos autores defienden que:

17. Fraser, N. y Honneth, A. ¿Redistribución o reconocimiento? Un debate político-filosófico, Madrid, Morata, pp. 129-133.

18. Buchanan, A. y otros: op. cit., p. 67.

19. Ibidem, p. 288.

Thémata. Revista de Filosofía $\mathrm{N}^{\circ} 55$ (2017) pp.: 65-82. 
los costes de cambiar la sociedad para hacer que una gran disfunción como la sordera no plantee limitaciones a las oportunidades de los individuos no son tan fácilmente desechables. Estos costes cuestan desde un punto de vista moral, porque hay un interés moralmente legítimo por evitarlos ${ }^{20}$.

La explicación de este interés, según argumentan, es que entienden que hay un problema previo de justicia, no referido a la distribución sino a la producción: la elección del marco cooperativo dominante ${ }^{21}$, es decir, del conjunto de infraestructuras físicas e institucionales subyacentes en la interacción social. Desde su punto de vista, si se acepta lo que piensan los defensores de las personas con diversidad funcional, habría que partir de la idea de que la discapacidad es de naturaleza social: alguien es incapaz de algo por referencia a un marco cooperativo determinado. Por eso mismo, es necesario apoyar la «moral de la inclusión»:

La elección de un esquema cooperativo dominante es cuestión de justicia porque determina quién es discapacitado y quién no, y porque el que una persona sea discapacitada tiene profundas consecuencias para su posición en la sociedad, sus oportunidades y sus perspectivas de vida generales. Debido a las ventajas económicas y sociales que proporciona el poder participar eficazmente en el esquema cooperativo dominante, los individuos tienen un interés fundamental para no ser discapacitados, es decir, que sus capacidades estén a la altura de lo exigido por el esquema cooperativo dominante. Este es el interés por la inclusión ${ }^{22}$.

Sin embargo, entienden que enfrente de esta postura también hay otro interés legítimo, no tenido en cuenta por los defensores de las personas con diversidad funcional:

Hay un interés opuesto al que un orden social justo concederá peso: el interés maximizador. Cada individuo tiene un interés importante y moralmente legítimo de tener acceso al esquema cooperativo que constituya la forma más productiva y satisfactoria de interacción en la que pueda participar activamente /.../ también pierden algo de valor aquellos que podrían participar en un esquema más productivo y satisfactorio pero se ven impedidos por restricciones para hacer el esquema más inclusivo ${ }^{23}$.

20. Ibidem, p. 264.

21. Ibidem, pp. 269-278.

22. Ibídem, p. 271.

23. Ibídem, pp. 271-272.

Thémata. Revista de Filosofía $\mathrm{N}^{\circ} 55$ (2017) pp.: 65-82. 
Aún reconociendo que las personas con diversidad funcional más grave tienen derecho a que se les respete su igual dignidad moral, consideran que es necesario armonizar ambos intereses legítimos, para que los individuos puedan participar plenamente en el esquema cooperativo dominante. Es aquí en donde entran en juego las intervenciones genéticas: estas permiten armonizar ambos intereses, de forma que se trabaje en contra de la exclusión del marco cooperativo dominante.

A pesar de que estos autores reconocen la igual dignidad de todas las personas, hay algo que, desde nuestro punto de vista, chirría en el desarrollo de su argumentación. En tal sentido, Nussbaum muestra su perplejidad ya en un artículo ${ }^{24}$ de 2002 — por tanto, anterior a su aplicación del enfoque de las capacidades a la problemática de las personas con diversidad funcional en Las fronteras de la justicia - , en la medida en que estos autores vienen a cuestionar a las personas que no tienen el funcionamiento normal de la especie. En tal sentido, Nussbaum critica la obsesión por la normalidad:

sabemos que muchas de las vidas humanas más valiosas y creativas son el resultado de una lucha especialmente difícil que alejó a ciertas personas de lo convencional y las convirtió en blanco del desprecio y el insulto de sus iguales. /.../ Si todos los niños pueden ser creados conforme a cualesquiera que sean las normas dominantes en la sociedad, ¿no se empobrecerá por ello la vida humana? ${ }^{25}$

Nussbaum es partidaria de crear una cultura pública que respete las diferencias en el funcionamiento humano, puesto que todas las vidas humanas son igualmente valiosas y no solo las que se ajustan a los parámetros de normalidad. No obstante, es en Las fronteras de la justicia, publicada en 2006, donde Nussbaum adopta una posición sobre el tema enfrentada - al menos parcialmente - a lo defendido por Buchanan y otros en Genética y justicia. Puede decirse que en esta obra, en la que aplica su enfoque de las capacidades a la problemática de injusticia hacia las personas con diversidad funcional, se trasluce el apoyo de Nussbaum al modelo

24. Nussbaum, M.: "Genética y justicia: tratar la enfermedad, respetar la diferencia", Isegoría, 27 (2002), pp. 5-17.

25. Ibidem, pp. 15-16.

Thémata. Revista de Filosofía $\mathrm{N}^{\circ} 55$ (2017) pp.: 65-82. 
social de la discapacidad ${ }^{26}$, cuestionado parcialmente por estos autores. Este acercamiento al modelo social justifica la introducción, por parte de Nussbaum, de un argumento crítico de mayor contundencia hacia lo defendido por Buchanan y otros: el igual derecho político que tienen todas las personas para que se produzca un empoderamiento de sus capacidades centrales hasta un mínimo, como exigencia de justicia, con independencia del marco cooperativo elegido. Lo cual supone potenciar las transformaciones sociales (accesibilidad, etc.) necesarias, aunque sin cerrar, por ello, la puerta a las intervenciones genéticas. Los ciudadanos con diversidad funcional tienen los mismos derechos que el resto de ciudadanos, hasta el mínimo decente fijado, para que se acometan los cambios necesarios en el espacio público inclusivo, del mismo modo que se acometen gastos para las personas que funcionan normalmente en dicho espacio público. Hasta hace escasas décadas, lo que ha ocurrido es que la sociedad ha ignorado las necesidades atípicas de las personas con diversidad funcional y únicamente atendía, mediante los recursos y la implementación de políticas, las necesidad típicas de los ciudadanos. Atender ahora las necesidades atípicas de los ciudadanos no supone más que una justa movilización de recursos tendentes a acomodar el espacio social para aquellos que antes eran excluidos, garantizando de ese modo el igual derecho de todos a ocupar dicho espacio social27. Así, por ejemplo, como en las ciudades se instalaron semáforos para la seguridad de los peatones videntes, ahora también deben instalarse semáforos con sonido para las personas ciegas.

Recurriendo a la ética discursiva, podemos reforzar la crítica a la argumentación basada en la elección del marco cooperativo. Este refuerzo crítico es necesario porque, como señala Forst ${ }^{28}$, el enfoque de las capacidades de Nussbaum atiende a la justicia en la distribución pero no aborda el problema previo al que aluden Buchanan y otros: la justicia referida a la producción. Aun cuando estos autores son conscientes de que el actual marco cooperativo de producción (la economía simbólica e industrial) no ha sido elegido, parecen sugerir que, en el caso de que lo fuera, los intereses de las personas con diversidad funcional y sus defensores y los intereses opuestos de otras personas se formarían en privado ${ }^{29}$. Sin embargo, si en-

26. Tanto los defensores del modelo social como Nussbaum sostendrían: a) la no separación entre lo natural y lo social, b) el rechazo a la diferenciación entre lo privado y lo público, c) el cuestionamiento de la distinción entre normalidad y anormalidad y d) la afirmación de la continuidad entre independencia y dependencia. Cabría interpretar, pues, que la aplicación del enfoque de las capacidades desplegada en Las fronteras de la justicia asume estos supuestos fundamentales del modelo social.

27. Nussbaum, M.: Las fronteras de la justicia, Barcelona, Paidós, 2006, pp. 128-129.

28. Forst, R.: Justificación y crítica, Madrid, Katz, 2014, pp. 39-41.

29. Buchanan, A. y otros: op. cit., p. 320.

Thémata. Revista de Filosofía $\mathrm{N}^{\circ} 55$ (2017) pp.: 65-82. 
tendemos que, en el seno de una democracia deliberativa ${ }^{30}$, la elección del marco cooperativo de producción ha de venir precedida de la correspondiente deliberación, entonces habría que entender, más bien, que las preferencias sostenidas individualmente se forman socialmente y, por tanto, que las diferencias existentes están sujetas a transformación a través de la argumentación.

Desde una concepción comunicativa de la democracia como la propuesta por Cortina ${ }^{31}$, siguiendo a Habermas, las normas de justicia subyacentes a dicho marco cooperativo, para contar con legitimidad, han de establecerse teniendo en cuenta la deliberación pública. Si se quiere lo justo, entonces ya siempre tenemos que partir del reconocimiento recíproco de quienes participan en la deliberación mediante la comunicación y el discurso argumentativo; ellos son reconocidos ya como interlocutores válidos - directamente, con asistencia o mediante representación-, en tanto que están afectados por tales normas. Como indica Apel ${ }^{32}$, es en el discurso en donde se toman en consideración todas las necesidades de los participantes en el mismo, en tanto que exigencias dirigidas comunicativamente a los demás miembros de la comunidad deliberante, las cuales se justifican mediante argumentos. Es decir, es en la comunicación y en el discurso en donde habrán de aflorar las necesidades atípicas, sin que quepa, para que la deliberación tenga legitimidad, su exclusión. Por otra parte, también se presupone el reconocimiento social (Honneth), para que todos los miembros de la sociedad, en tanto que participantes en la deliberación democrática, tengan libertad para poder determinar lo correcto ${ }^{33}$.

En la deliberación, ya siempre se presupone la eliminación de las asimetrías y el reconocimiento de iguales derechos «humanos» ${ }^{34}$ a los participantes. En este sentido, una democracia deliberativa también presupone la modulación de los derechos humanos recogida en la Convención Internacional sobre los Derechos de las personas con discapacidad, aprobada por la $\mathrm{ONU}$ en 2006, como fruto de las luchas por el reconocimiento llevadas a cabo por tales personas y quienes les apoyan. El núcleo normativo ${ }^{35}$ de

30. Habermas, J.: "Tres modelos normativos de democracia" en La inclusión del otro, Barcelona, Paidós, 2008, pp. 231-246.

31. Cortina, A.: Justicia cordial, Trotta, Madrid, 2010, pp. 87-94.

32. Apel, K.O.: La transformación de la Filosofía, II, op. cit., p. 404.

33. Honneth, A.: "La ética discursiva y su concepto implícito de justicia", en Apel, K.O., Cortina, A., de Zan, J. y Michelini, D. (eds.): Ética comunicativa y democracia, Barcelona, Crítica, 1991, p. 173.

34. Cortina, A.: Justicia cordial, Madrid, Trotta, 2010, pp. 112-116.

35. Palacios, A: El modelo social de la discapacidad: orígenes, caracterización y plasmación en la Convención Internacional sobre los Derechos de las Personas con Discapacidad, Madrid, Ediciones Cinca, 2008.

Thémata. Revista de Filosofía $\mathrm{N}^{\circ} 55$ (2017) pp.: 65-82. 
tal documento moral-jurídico internacional es tanto la no discriminación de las personas con diversidad funcional como el aporte de herramientas para que las mismas gocen y ejerciten tales derechos. Se trata, en suma, de remover las barreras sociales que impiden la igualdad jurídica. Dada la diversidad corporal existente, para que pueda ser efectiva la igualdad de derechos humanos, esta ha de incorporar también iguales condiciones de acceso a estos derechos (por ejemplo, la accesibilidad mediante el uso del lenguaje de signos, en el caso de las personas sordas, o la accesibilidad cognitiva en la comunicación, en personas con diversidad cognitiva). Así pues, las transformaciones sociales, de acuerdo a unos mínimos de justicia, no están sujetas - pese a lo que plantean Buchanan y otros- a deliberación, sino que constituyen, más bien, un presupuesto suyo, si es que se pretende que la deliberación pueda tener validez. En un marco democrático-deliberativo, tales transformaciones sociales, guiadas por los derechos recogidos en la Convención de 2006, son la garantía para eliminar las asimetrías sociales existentes y situar a las personas con diversidad funcional como ciudadanos autónomos — directamente, con asistencia o por medio de representante- que deliberan en torno a las normas regulatorias del marco cooperativo para la producción.

Ahora bien, desde este marco normativo, no queda tampoco cerrada la puerta a las intervenciones genéticas terapéuticas en caso de enfermedades graves. Podría aducirse que - al menos bajo ciertas condiciones morales y políticas - las intervenciones genéticas quedan también legítimamente incorporadas en las citadas transformaciones sociales. Podría parecer, entonces, que se hacen innecesarias las condiciones sociales de accesibilidad, dado que los individuos que, una vez corregida su estructura genética, naciesen podrían tener el funcionamiento normal de la especie. Frente a esta objeción, lo que queda, en último término, es apelar a la existencia de la vulnerabilidad humana. Ciertamente, aunque esta constituye un hecho característico de lo humano, una sociedad justa debe tratar de impulsar una medicina -incluyendo la terapia genética- que luche contra la misma. No obstante, resulta un imposible pensar que puede erradicarse toda forma de vulnerabilidad física. Aunque se corrija la vulnerabilidad genética y, en conjunto, disminuya la vulnerabilidad física existente en la sociedad, esta seguirá presente. Gracias a los avances médicos, el número de personas con diversidad funcional podría ser menor; no obstante, seguirá siendo necesario que, para el mantenimiento de la simetría y los iguales derechos como miembros de la comunidad política deliberante, se presuponga ya siempre las condiciones sociales de accesibilidad en el conjunto de los derechos, recogidas en la Convención de 2006. Por eso mismo, desde el punto de vista de la democracia deliberativa, someter a un consenso fáctico el mantenimiento o no de las mismas sería incurrir en 
una contradicción performativo-práctica. En tal caso, se violaría, para la minoría de ciudadanos con necesidades atípicas, la igualdad de derechos y de accesibilidad a los mismos. En suma, la ética discursiva permite que podamos disponer de un criterio normativo para la crítica de la elección democrática de un marco cooperativo. Y esto con independencia de que puedan usarse intervenciones genéticas terapéuticas, las cuales tendrían que contar con unos mínimos de justicia distributiva.

\section{Un marco normativo ético-político para la genética terapéutica}

Cortina propone definir el marco ético ${ }^{36}$ que cabe utilizar para la defensa de la genética terapéutica. Teniendo en cuenta sus propuestas, junto a las aportaciones de Habermas y de Honneth, podemos esbozar brevemente un marco normativo ético-político al que tendría que ajustarse la nueva genética:

1) Es necesario partir de un enfoque kantiano, considerando que el fundamento moral de la justicia con las personas con diversidad funcional lo constituye la dignidad de la persona. Como señala Cortina, la persona no es, para Kant, únicamente un fin limitativo, lo que se traduce en la obligación moral de no dañarlo. También debe ser un fin positivo, es decir, existe el deber de empoderarlas, mediante las correspondientes transformaciones sociales, para que puedan llevar una vida con dignidad. Hay que distinguir claramente, pues, entre dignidad de la persona con diversidad funcional, perteneciente a un plano normativo, y la posesión fáctica de una diversidad funcional. Por eso, el hecho de que se prevengan algunos tipos de diversidad funcional graves, mediante el uso de técnicas médicas, no afecta a la dignidad de las personas con diversidad funcional. En tal sentido, Michelini ${ }^{37}$ considera que, de acuerdo con el pensamiento de Kant, la dignidad se atribuye a todo ser humano, no en cuanto individuo de la especie humana sino como miembro de la comunidad de los seres morales. Poseen dignidad, por tanto, todos los miembros de la especie humana en tanto que miembros de la comunidad de seres morales. Por ello, considera que, desde la perspectiva kantiana, las circunstancias contingentes (pérdida de la capacidad de comunicarse, de interactuar, etc.) que afectan a los individuos de la especie no afectan a su pertenencia a la comunidad de seres morales. Este autor distingue, pues, entre los criterios empíricos y el plano moral: las contingencias que mermen o anulen ciertas capacidades,

36. Cortina, A.: "Ética de las biotecnologías" en Isegoría, 27 (2002), pp. 73-89.

37. Michelini, D. "Dignidad humana en Kant y Habermas", en Estudios de Filosofía Práctica e Historia de las Ideas, Vol. 12 n ${ }^{\circ}$, Mendoza, Julio 2010, pp. 41-49.

Thémata. Revista de Filosofía $\mathrm{N}^{\circ} 55$ (2017) pp.: 65-82. 
empíricamente constatables, no constituyen criterios adecuados ni para negar el estatus de ser digno a tales personas ni para dejar de considerar su humanidad en tanto que seres morales. Resultaría arbitrario, de acuerdo con esta interpretación, excluir la dignidad en el caso de seres humanos con diversidad funcional mental o cognitiva porque, con ello, se estaría apelando a un criterio empírico, no moral.

2) Por otra parte, no podemos olvidar que las personas son seres corporales y, por tanto, seres vulnerables que luchan contra las enfermedades que tienen, usando, para ello, las técnicas terapéuticas aportadas por la medicina. Esta lucha contra la vulnerabilidad no solo no va en detrimento de la dignidad personal; por el contrario, cuando hay personas a las que no se atiende en sus enfermedades con las técnicas existentes, entonces decimos que no tienen una vida acorde con la dignidad. De modo análogo, el hecho de que pretendan prevenirse en embriones las diversidades funcionales, usando ahora técnicas terapéuticas genéticas, no afecta a su dignidad; más bien, cabría decir, por el contrario, que no tendría una atención acorde con la dignidad si las técnicas estuvieran disponibles y sus padres no pudiesen utilizarlas, en caso de querer dar su consentimiento. Por eso mismo, como proponen Buchanan y otros, se requieren unos mínimos de justicia distributiva para que quienes tienen menos recursos, puedan disponer de esta posibilidad.

3) Entendemos, en el marco de la teoría de la justicia como reconocimiento de Honneth, que a raíz de las luchas por el reconocimiento, la sociedad ha empezado a adoptar las medidas sociales necesarias para favorecer el reconocimiento social de las personas con diversidad funcional. Desde el punto de vista de una sociedad justa, esto supone la necesidad de contar con un trato igual a todos los individuos, en el sentido de que todos los individuos merecen por igual el reconocimiento de su necesidad (cuidado), de su igualdad jurídica (respeto) y de su mérito (valoración social), como apoyo al logro de la autorrealización ${ }^{38}$. Por otra parte, la concreción de la igualdad distributiva, no contemplada en detalle por Honneth, requiere apelar al enfoque de las capacidades de Sen y Nussbaum: son las capacidades básicas, que la sociedad concreta mediante el razonamiento público en lo que respecta a su nivel mínimo, las que es necesario empoderar en una persona para que pueda hacer o ser lo que tiene razones para valorar (en el caso de personas con diversidad intelectual, los correspondientes funcionamientos).

4) En los debates públicos, tanto de la sociedad civil como en el ámbito parlamentario, en los que se delibere sobre cuestiones genéticas,

38. Honneth, A.: "Redistribución como reconocimiento" en Fraser, N. y Honneth, A.: ¿Redistribución o reconocimiento?, Madrid, Morata, 2006, pp.89-148.

Thémata. Revista de Filosofía $\mathrm{N}^{\circ} 55$ (2017) pp.: 65-82. 
con el fin de que el legislador pueda determinar aquellas intervenciones genéticas terapéuticas que, desde un punto de vista político, habrán de permitirse, deben estar representadas las personas con diversidad funcional -directamente, con asistencia o por medio de representante. Lo que se pretende es que pueda disponerse de argumentos complementarios, que ayuden a corregir concepciones inadecuadas acerca de lo que es la vida de una persona con diversidad funcional. También que pongan en guardia contra los abusos posibles de la nueva genética, en lo que respecta a la desvalorización de quienes puedan tener defectos genéticos. No obstante, esto no implica que esta voz, aunque tenga que ser escuchada, haya de ser la única que sea tenida en cuenta.

5) Puesto que la decisión de la intervención genética corresponde a los padres, es necesario contar con el ejercicio de su autonomía, ejercida bajo el derecho al consentimiento informado. En tal sentido, se debe contar con una información adecuada, completa y veraz del tipo de diversidad funcional que afecta al embrión, para que puedan tomarse las decisiones que se estimen adecuadas con conocimiento de causa.

6) Como indica Habermas ${ }^{39}$, para afrontar situaciones en las que se recurre a la genética terapéutica resulta conveniente, más allá de las preferencias subjetivas, la adopción de un criterio normativo: el consenso discursivo que debe tener en cuenta a todos los afectados por la decisión. Lo cual supone adoptar, en relación al embrión, la perspectiva del participante. Se trata, pues, de considerarlo, al menos contrafácticamente, como un interlocutor válido. En dicha situación hay que atender dos puntos de vista: a) el punto de vista moral de no instrumentalizar a segundas personas, evitando con ello los peligros de la vieja eugenesia. Será necesario partir de la suposición contrafáctica de un consenso con otro y que (según suponemos) tiene interés en evitar una vida limitada y b) el punto de vista de los padres que deberían verse capaces de asumir su responsabilidad con un hijo con el que compartirán su vida —incluso en una sociedad justa con las personas con diversidad funcional - con ciertas limitaciones.

En este contexto ético-político planteado, la decisión autónoma y responsable corresponderá a los padres. Habermas entiende que el debate público se reavivará cuando el legislador introduzca un nuevo tipo de intervención para actuar sobre una enfermedad genética grave. El legislador tiene que justificar ampliamente tal aumento de la lista de intervenciones genéticas, ya que se traslada a los padres la responsabilidad por tal decisión, en caso de que no quieran usar el permiso abierto por la ley. A su vez, los padres que rechacen la ley y acepten una diversidad funcional grave

39. Habermas, J.: El futuro de la naturaleza humana. ¿Hacia una eugenesia liberal?, Barcelona, Paidós, 2009.

Thémata. Revista de Filosofía $\mathrm{N}^{\circ} 55$ (2017) pp.: 65-82. 
evitable, han de enfrentarse al reproche social y, en su caso, al reproche de su hijo en el futuro. Habermas expresa, no obstante, su inquietud por el hecho de que «hagamos por otros una distinción tan rica en consecuencias entre una vida que merece vivirse y una vida que no merece vivirse». En todo caso, tampoco podemos olvidar que corresponde a la sociedad sentar las bases justas para que toda vida humana sea una vida acorde con la dignidad. 